\title{
De Espectador à Produtor de Imagens: Seguindo Pistas do Trabalho com Stop Motion na Educação
}

\section{From Spectator to Producer of Images: Following Clues of the Working with Stop Motion in Education}

\begin{abstract}
Resumo: Este artigo apresenta o resultado de experiências com a técnica de animação em stop motion em cursos de formação de professores. As potencialidades da utilização da técnica em contexto educacional são analisadas à luz dos trabalhos de Walter Benjamin, Roland Barthes, Vanessa Schwartz e Jeannene M. Przybyski, entre outros, sobre fotografia, cinema e a imagem na modernidade. São discutidos o surgimento da figura do espectador na modernidade e os impactos da fotografia na subjetividade, na percepção do tempo e da realidade, bem como os conceitos benjaminianos de inconsciente ótico, montagem e imagem dialética. O trabalho discute como a utilização da técnica do stop motion pode favorecer a passagem dos sujeitos da condição de espectadores para a de produtores de imagens, permitindo outra compreensão e tomada de consciência dos usos e sentidos das imagens na cultura contemporânea e em contexto digital, bem como outras experiências de tempo e subjetivação na educação.

Palavras-chaves: Imagem e Educação. Fotografia e Educação. Stop Motion e Educação. Walter Benjamin. Tecnologia e Educação.
\end{abstract}

Abstract: This article presents the result of experiments with the technique of stop-motion animation in teacher training courses. The potential uses of the technique in an educational context are analyzed in light of the work of Walter Benjamin, Roland Barthes, Vanessa Schwartz e Jeannene M. Przybyski, among others, about photography, cinema and image in modern days. We discuss the advent of the spectator in modern days and the impact of photography in subjectivity, in the perception of time and reality, as well as Benjamin's concepts of optical unconscious, editing and dialectical image. The work discusses how the use of the stop-motion technique can favor the transition of subjects from the condition of spectators to the condition of image producers, allowing another kind of understanding and consciousness of the use and sense of images in contemporary culture and in digital context, as well as other experiences of time and subjectivation in education.

Keywords: Image and Education. Photography and Education. Stop-motion and Education. Walter Benjamin. Technology and Education.

MONTEIRO, Aline Veríssimo; SANTI, Angela Medeiros; FERREIRA, Aurélia Navarro de Andrade Cintra. De Espectador à Produtor de Imagens: seguindo pistas do trabalho com stop motion na educação. Informática na Educação: teoria e prática, Porto Alegre, v. 17, n. 2, p. 131-147, jul./dez. 2014.

\section{Aline Veríssimo Monteiro}

Universidade Federal do Rio de Janeiro

Angela Medeiros Santi

Pontifícia Universidade Católica do Rio de Janeiro

Aurélia Navarro de Andrade

Cintra Ferreira

Universidade Federal do Rio de Janeiro

\section{Introdução}

E m um contexto cultural marcado por rápidas transformações e interações via tecnologias digitais de comunicação, troca e produção de imagens, educar passa a ter como desafio e objetivo preparar sujeitos que dominem e compreendam bem essas dinâmicas, podendo delas fazer uso na direção de seu pleno desenvolvimento, participação e colabo- 
ração social. Este artigo pretende refletir sobre a cultura contemporânea e seus impactos sobre a educação, a partir da apresentação de experiências com stop motion ${ }^{1}$ na formação de professores ${ }^{2}$. Trata-se de três atividades desenvolvidas com esta técnica de animação na forma de curso e oficinas para professores formados e em formação, todas realizadas na Universidade Federal do Rio de Janeiro. Com essas experiências, pudemos refletir e explorar potências e possibilidades que a fotografia, e sua utilização na animação em stop motion, apresenta em dinâmicas educacionais favorecendo a autoria, a expressão e a construção do conhecimento pelos participantes. Questões como capacidade de síntese, construção narrativa, planejamento, trabalho de grupo, organização, vivências complementares entre produções e contextos analógicos e digitais são alguns dos elementos mobilizados e experimentados pelo uso desta técnica. Fundamentam teoricamente essas propostas trabalhos de Walter Benjamin e Barthes sobre a fotografia, e estudos sobre a constituição da modernidade, a partir da fotografia, do cinema e de outras manifestações artísticas e culturais.

Tal como vivenciamos, o trabalho com o stop motion demonstrou permitir uma inversão do lugar onde normalmente se situam alunos e professores na relação com a imagem na educação, e também todos nós diante das mídias cotidianamente: o lugar de espectador. A técnica parece favorecer o desenvolvimento de uma consciência do que é a imagem e de suas características específicas: sua condição associada à montagem, ligada tanto à ima-

\footnotetext{
${ }^{1}$ O stop motion é uma técnica de confecção de filmes de animação que trabalha a partir de fotografias.

2 Essas experiências integram o conjunto de ações desenvolvidas pelo projeto de pesquisa e extensão Imagem, Texto e Educação Contemporânea (ITEC), ligado ao Laboratório do Imaginário Social e Educação (LISE), da Faculdade de Educação, da UFRJ.
}

gem parada (cada fotografia em si), quanto à imagem em movimento (o filme resultante do trabalho de edição). O trabalho com o stop motion permitiria, também, tanto uma educação para a imagem como uma educação para o contemporâneo. Os trabalhos de Benjamin e de Barthes contribuem para essa compreensão, na medida em que desenvolvem uma análise sobre a imagem, a fotografia, e seu impacto sobre as subjetividades. As considerações dos autores sobre a fotografia como forma mecânica de captura de imagens, onde a autoria se encontra deslocada e partilhada entre máquina e homem, trazem importantes pistas para pensarmos as questões da representação e do tempo provocadas pela técnica e ampliadas pelas tecnologias digitais portáteis contemporâneas.

Em Benjamin (2006), uma noção importante para este trabalho é aquele de montagem, que ele identifica ao ato de isolar as partes, separando-as de seu contexto original e construindo novos. Ao percebemos tal dinâmica, tornamo-nos conscientes do que era, até então, imperceptível, entendendo a condição fragmentária e montada que constitui as totalidades (no filme, na novela, no telejornal, nas imagens publicitárias, etc.) que chegam até nós como prontas e acabadas. Na medida em que identifica, em parte, os elementos constitutivos da imagem e da cultura contemporânea, o trabalho com o stop motion coloca os sujeitos na condição de sujeitos de um processo de construção de narrativas, através de uma sequência de imagens, antes isoladas, visando contar uma história. Já em Barthes, suas reflexões sobre a câmara clara e as mudanças sobre regimes de tempo e representação são significativas para as reflexões que pretendemos estabelecer aqui. 
Para compor o quadro sobre a importância e positividade do trabalho com o stop motion no contexto da sociedade contemporânea, resgatamos alguns estudos sobre os primórdios de constituição da figura do espectador em uma sociedade de massa. Em O Espectador Cinematográfico Antes do Aparato do Cinema: o gosto do público pela realidade na Paris fim de século, Vanessa Schwartz (2004) retoma o fim do século XIX, em Paris, mostrando o surgimento de uma nova cultura de massa, repleta de novos espetáculos que proporcionavam aos espectadores situações distantes de sua realidade, porém reais. O necrotério de Paris, os museus de cera, como o Musée Grévin, e os Panoramas eram algumas das atividades frequentes oferecidas à população local, analisadas pela autora, permitindo a compreensão do processo de constituição da figura do espectador. Em função de tais espetáculos, surge um voyeurismo que não estava mais restrito aos nobres e burgueses, mas tornara-se um voyeurismo de massa. De posse dessa contextualização, entendemos melhor a constituição da cultura contemporânea, ligada à imagem em suas diferentes plataformas tecnológicas, permitindo, a partir da experiência com o stop motion, uma virada a favor de um trabalho pedagógico que coloque professores e alunos não só como observadores, mas como agentes da construção de imagens significativas.

\section{Modernidade e a Construção do Espectador}

Para entender como, desde a Modernidade, a imagem foi ganhando importância, como nossa relação com ela nos coloca na posição de espectadores passivos e refletir sobre a imagem na cultura contemporânea, partiremos sobretudo da obra de Benjamin e do artigo de Schwartz (2004). Benjamim, em Pequena História da Fotografia (1986b), atenta para o fato de que, com o advento da fotografia, o ser humano sofre um deslocamento do papel de sujeito, passando a ser objeto de registro.

Schwartz (2004) descreve como, na Paris do fim do século XIX, é possível notar esse fenômeno num dos programas culturais favoritos dos parisienses: a visita ao necrotério de Paris. Nele, o público tinha contato com a realidade nua, crua e cadavérica: o real era espetacularizado, proporcionando um misto de prazer e diversão, impossibilitando a distinção entre ficção e realidade. A vida tornava-se um espetáculo que deveria ser observado. Existia um prazer no desejo de olhar que não estava mais restrito somente ao burguês rico, mas que se estendia à população em geral, uma vez que não era cobrada entrada ao necrotério. Nele, eram reconstruídas as cenas das notícias e histórias retratadas nos jornais, reforçando-as. Tendo esse cenário exposto, o público usava da sua imaginação para reconstituir o que lhes era mostrado. Com o necrotério, as pessoas podiam estar em contato com as personagens retratadas pela imprensa, ajudando a criar uma cultura de massa.

Com o fechamento do necrotério, nos diz a autora, ganham notoriedade o Musée Grévin e os Panoramas, que davam continuidade à exploração da realidade. Demonstrando já a dominância da cultura de massa, essas outras duas atividades, apesar de serem espaços de arte, vão tentar ganhar aprovação, não dos críticos, mas, sim, do público. O Musée Grévin, desde a sua estreia, se aproveita da popularidade do necrotério, que trabalhava com o real e o espetacular, para atrair o público parisiense:

Quando o Musée Grévin foi inaugurado, em 1882, no Bulevar Montmartre, no coração da 
Paris 'moderna', um cartum de jornal associou o museu de cera ao já popular necrotério. Nele, dois operários olham boquiabertos uma figura de cera estendida em uma laje. Um diz: 'Uau, parece um cadáver de verdade'. Seu amigo responde: 'Isso é quase tão divertido quanto o necrotério. (SCHWARTZ, 2004, p. 345)

Segundo seus fundadores, o museu tinha por objetivo ser um aprimoramento dos jornais. Para eles, a escrita não era o bastante para reter a atenção do público, que precisaria de imagens que ilustrassem os fatos diários. A mesma ideia parece estar presente no Musée Grévin, que pretendia criar um jornal plastique, ou seja, um jornal que explorasse a plasticidade estética, que iria se modificando de acordo com o gosto da massa. Afinal, ao recriar uma cena, tinha a preocupação de narrar um acontecimento com os mínimos detalhes e caberia ao espectador averiguar a legitimidade da cena.

Para Schwartz (2004), a partir desses dois eventos, que conseguiram cativar o gosto desses novos espectadores, já poderíamos observar o surgimento de um flaneur, isto é, um observador, possuidor de um olhar errante, que capta de forma atenta as atividades culturais de seu tempo. Esse espectador, ao frequentar esses espaços, mesmo que inconscientemente, começava a treinar o seu olhar.

Assim, quando surge o cinema, o espectador já tem sua apreciação direcionada para determinado tipo de produção, o público tem a necessidade de se ver representado nesses mecanismos artísticos e de perpetuação da imagem, tamanho é o gosto pela realidade que o circunda. Aquele que observa, e para quem são destinadas as imagens produzidas, é vítima de uma passividade sistemática. Por ignorar o processo de produção, torna-se um mero receptáculo imagético e se aliena do que é representado, prejudicando o entendimento do que é produzido e caindo numa percepção superficial do que é transmitido.

Em uma sociedade repleta de imagens, como a nossa, muitas vezes o entendimento fica prejudicado, afinal, há tanto para se ver que, se formos parar para analisar e refletir sobre tudo o que é mostrado, um turbilhão de imagens será perdida e, com elas, parte da realidade a ela atrelada. Uma vez que a reflexão é processual, se faz necessário tempo e atenção para analisar o que é transmitido, assim, estamos sempre atrasados em relação ao fluxo de imagens. Este é o caso do que acontece contemporaneamente, por exemplo, nas interações provenientes das redes sociais, onde há constante troca e produção de imagens. No entanto, este processo se dá de forma indiscriminada, e o que poderia tornar as relações muito mais ricas de conteúdo e criticidade, acaba perdendo seu potencial de ação e torna-se algo vazio de conteúdos e significados. Ao mesmo tempo em que as imagens têm um caráter de produção individual, como os posts de cada perfil da rede social, ela é, paradoxalmente, fruto da massificação, devido à reprodução não só de formas, mas também de conteúdos.

Aqueles que mais são afetados pelas produções imagéticas são os jovens que fazem uso constante de televisão, internet e redes sociais. Com as tecnologias portáteis todos podem ter acesso, de qualquer lugar, a diversos conteúdos, e as imagens encontram nesse suporte tecnológico, um espaço muito amplo onde podem ser exploradas de diversas formas. Mas todo esse acesso não garante uma relação consciente, ativa e criativa com a imagem. A necessidade de velocidade e de atingir um número cada vez maior de espectadores 
parece favorecer a utilização de imagens em detrimento do texto, que está sendo reduzido e ganhando características típicas da imagem: ênfase na síntese, na sensorialidade e na estética visual.

Um ambiente onde a tensão entre texto e imagem pode ser fortemente sentido e, por isso também, muito propício para a exploração da utilização da imagem em concomitância com o texto, é o ambiente educacional. Há tempos os professores já enfrentavam problemas relacionados à falta de interesse dos alunos e, com o advento da internet, esse desinteresse pelo conteúdo em sala de aula se tornou mais forte. $\mathrm{Na}$ busca por conquistar o interesse do aluno, unir o saber que ele já possui, com o qual tem familiaridade e compõe seu cotidiano, ao saber escolar formal, pode ser uma maneira mais eficaz de atrair o discente e conectá-lo à escola. Este é um dos pontos em que entendemos que o stop motion pode contribuir com a educação. Unindo o artesanal ao tecnológico, o tempo do fazer (mais lento) ao tempo da recepção (acelerado), a técnica favorece o tempo da educação, a demora exigida pela compreensão e pelo conhecimento, e a velocidade dos dispositivos digitais que todos utilizamos rotineiramente. Entretanto, antes de tratarmos da experiência com o stop motion, gostaríamos de explorar um pouco mais os elementos que envolvem a reflexão sobre a imagem fotográfica, em Barthes e Benjamin. Isto porque a fotografia é a base da animação em stop motion e, também, aquela que mais produzimos e recebemos cotidianamente nas redes sociais, aquela que parece ser o recurso mais frequente de afirmação visual de nossa subjetividade.

\section{Fotografia, Representação e Tem- po}

A passagem do século XIX ao XX pode ser considerada como o momento em que as tecnologias de imagem e visualidade produziram uma dinâmica moderna que podemos acompanhar até os dias de hoje. De certa forma, a partir dela podemos construir uma linha de continuidades e rupturas com a cultura contemporânea, de modo a nos permitir entender e encontrar alternativas para alguns dos desafios que nos são colocados na constituição de nossas subjetividades no século XXI. Das linhas de trem, passando por lojas de departamento, catálogos de compra, cartazes, a própria dinâmica e constituição da cidade moderna com grande centro urbano, museus de cera e cinema, temos a confluência de uma série de novos modos de mobilizar os corpos e as sensibilidades, as percepções e as sensações. Essa nova dinâmica visual e de fluxos teria contribuído para a construção de um sujeito moderno que oscila entre a atenção e a dispersão dentro de uma dinâmica econômica capitalista que opera entre a produção e o consumo. Esse sujeito produtor/consumidor é também aquele que se constitui como espectador dessa série de estímulos intensos e dispersos, precisando aprender a acompanhá-los e apreciá-los, se integrando e não sucumbindo a eles. Leo Charney e Vanessa Schwartz (2004) entendem que essa modernidade foi, sobretudo, um movimento de mudança da experiência subjetiva, que pode ser resumida como uma experiência cinematográfica. Nas palavras dos autores, "[...] a cultura moderna foi 'cinematográfica' antes do cinema." (CHARNEY; SCHWARTZ, 2004, p. 18), caracterizada por "[...] uma variedade de novas formas de tecnologia, representação, espetáculo, distra- 
ção, consumismo, efemeridade, mobilidade e entretenimento $[\ldots . .]^{\prime \prime}$ (CHARNEY; SCHWARTZ, 2004, p. 18).

A fotografia é um elemento importante nessa modernidade, uma vez que mobiliza aspectos relevantes dessas características, dentre os quais podemos destacar: a representação e a efemeridade. A primeira, por sua captura direta da imagem, sem a presença de um autor; a segunda, pela questão do tempo que vai ganhando importância cada vez maior conforme as máquinas vão ganhando velocidade instantânea nessa captura. Roland Barthes (1984), em A Câmara Clara, explora bastante a questão da proximidade da fotografia de seu referente e sua captura do instante efêmero. Para o autor, ela seria transparente, menos que um signo.

Seja o que for que ela [fotografia] dê a ver e qualquer que seja a maneira, uma foto é sempre invisível: não é ela que vemos.

Em suma, referente adere. E essa aderência singular faz com que haja uma enorme dificuldade de acomodar a vista à Fotografia. (BARTHES, 1984, p. 16)

Essa aderência do referente desafiaria a morte e o tempo, aprisionando um instante para sempre.

O que a fotografia reproduz ao infinito só ocorre uma vez: ela repete mecanicamente o que nunca mais poderá repetir-se existencialmente. Nela, o acontecimento jamais se sobrepassa para outra coisa: [...]; ela é o Particular absoluto, a Contingência soberana, [...]. (BARTHES, 1984, p. 13)

Essa de captura do tempo é também trabalhada por Jeannene M. Przyblyski (2004), mas em outra direção, como um desafio. Se Barthes (1984) ressalta como ela parece fa- zer o instante parar, a autora analisa como a fotografia foi convocada a capturar, imobilizar, a passagem do tempo, da história. Przyblyski (2004) examina como a fotografia foi desafiada na função de retratar a história e acontecimentos em movimento durante o surgimento do jornalismo fotográfico no evento da Comuna de Paris de 1871. Segundo a autora, os limites técnicos de captura de imagens em movimento desafiou a fotografia a criar convenções narrativas para poder representar as batalhas e os fatos da Comuna. A autora destaca a invenção de duas convenções narrativas fotográficas ao longo desse processo. A primeira que consistia em desdobramentos narrativos - sequências de fotos que, em seu conjunto, deveria poder representar a passagem dos acontecimentos, produzindo uma percepção de movimento. A segunda, compressão narrativa - fotos montadas, encenadas para serem fotografadas portanto, situações falsas que, justamente por serem falsas, poderiam melhor representar o verdadeiro sentido dos acontecimentos. Nessas montagens, eram reunidos os elementos ideais, nas posições mais favoráveis, para que se pudesse transmitir a informação desejada, soldados falsos em poses precisas que podiam conferir veracidade ao leitor/espectador da imagem. Analisando uma série de fotografias desse tipo, produzidas por Eugène Appert, a autora escreve:

[...] combinações do falso e do real, do objeto de cena e de relíquia, da camada espessa de ilusões próprias ao conto de fadas e da película envernizada da verdade documental, como as fotografias das barricadas, as composições de Appert também eram objetos hibridizados, complexas montagens de índices fotográficos e pelo modo como, contrariamente, complicavam a legibilidade de um ponto de vista fotográfico. (PRZYBLYSKI, 2004, p. 297) 
Essa tensão entre o falso e o real produzida pela transparência fotográfica gerou ainda outros efeitos, analisados por Benjamin, em seu ensaio sobre a história da fotografia. Destaca o autor que a fotografia subverte a ordem de importância da pintura, posto que o mais significativo em um retrato era o pintor e não o retratado. Porque a fotografia retém algo do sujeito que esteve realmente ali para ser fotografado, ela, de certa forma, torna extraordinário o ordinário, na medida em que se passa a fazer fotos de pessoas comuns, ilustres desconhecidos, imortalizados, imobilizados (BENJAMIN, 1986b). Também diz respeito a uma certa inversão de controle da imagem o fato de, com a fotografia e sua mecanicidade, podermos nos dar conta e vermos detalhes e aspectos invisíveis ao olho humano, naquilo que Benjamin (1986b) irá nomear como inconsciente ótico (que será desenvolvido mais adiante).

No jogo de representação e tempo/efemeridade promovido pela fotografia, Benjamin (1986b) ainda identifica que a questão do homem do mundo da reprodução é a transitoriedade e a reprodutibilidade, é a busca por uma proximidade que faz com que reconheçamos semelhanças mesmo no que é único. O fato de a fotografia ser uma reprodução técnica do mundo, e permitir reproduzir indefinidamente essa imagem, faz com que haja a perda da aura dos objetos e das artes mas, também, que haja uma democratização da arte e do mundo. No entanto, esse mundo sem aura não é apenas o das massas, mas também um mundo massificado. Ele aponta para outra sensibilidade, objetivada, a qual podemos ter acesso e consumir. O movimento e a história são editados e condensados em imagens fixas, que fixam percepções, como nos disse Przyblyski (2004). Nas palavras de Benjamin (1986b, p. 101): "Cada dia fica mais irresistível a neces- sidade de possuir o objeto de tão perto quanto possível, na imagem, ou melhor, na sua reprodução."

Talvez possamos, já aqui, ver pistas de nossa contemporânea produção/reprodução insistente de imagens/fotos. Ainda que Benjamin esteja escrevendo no início do século $X X$, a digitalização (máximo de reprodutibilidade até aqui) no séc. XXI, nos igualou a objetos, imagens de nós mesmos. E queremos possuir e ser possuídos, sem trégua. Queremos expressar ou produzir algo que valha por uma aura, uma unicidade a nosso respeito, mas isso só é possível no acompanhamento do fluxo de reprodução. Se pensarmos na produção de subjetividade nas páginas do Facebook, por exemplo, podemos ver que essa dinâmica de construção de unicidade se dá ao custo de sermos semelhantes a nós mesmos a todo o momento (pela quantidade de imagens fixadas), mas sendo diferentes de nós mesmos, a todo instante: temos que ser felizes, postando a qualidade de nossas vidas em momentos incríveis e novidades todos os dias, interessando e sendo interessantes, provando isso e dando nossas imagens como testemunho. Esse jogo entre quantidade e qualidade, de identidade e diferença, de certa forma reedita as duas convenções narrativas da fotografia apresentadas por Przyblyski (2004). Desdobramento narrativo pela quantidade de fotos que devem narrar nossa história, garantindo que sejamos sempre os mesmos sujeitos dessa história; e compressão narrativa, pois são sempre as meIhores imagens, fotomontagens da melhor versão de nós mesmos postadas. Versões que não existem para além daquela imagem capturada, que não se repetem no cotidiano, mas nos convencem pela insistência e permanência.

Na dinâmica contemporânea de circulação de imagens, as fotografias têm destaque, so- 
bretudo nas plataformas de redes sociais, mas também nas nossas experiências cotidianas, que parecem cada vez mais serem construídas e elaboradas para serem partilhadas digitalmente. Tiramos fotos para postar, para mostrar, para partilhar. Eventos têm seus espaços próprios para postagem de fotos instantaneamente, em tempo real, em Instagram, Facebook, e o que mais se desejar. As festas, as crianças, as paisagens, precisam ser registradas pelas lentes, mas cada vez menos paramos para olhar essas fotos como em seu tempo de revelação e impressão analógicas. O espaço da foto digital, e também do filme digital, é a rede, o fluxo, a nuvem, e sua produção parece ter mais a ver com acompanhar digitalmente $o$ fluxo, digitalizar a experiência (como uma espécie de filmagem do cotidiano), do que com acumular e colecionar para ter e guardar. O registro digital é uma captura do instante que se quer para o próprio instante, para o presente. É como se quiséssemos materializar a experiência, externalizar imagens mentais, sensações e afetos, e partilhá-los, recorrendo àquilo que produzimos de mais parecido com elas: conexões em redes de informações digitais em vez de redes neurais; fluxos de bits em vez de fluxos eletroquímicos. Essa externalização do mental, essa subjetividade pret à porter para ser consumida, partilhada pelos outros, aparece em discursos sobre o cinema e sua narrativa feitos no início do século $X X^{3}$. Todos agora viramos como que cineastas de nossas vidas e vivemos de acordo com isto, sempre voltados para as câmeras, sempre prontos para sermos

\footnotetext{
${ }^{3}$ Cf. H. Munsterberg, 1916 (XAVIER, 1983). O autor apresenta uma série de considerações sobre os efeitos do cinema na atenção, na memória, na imaginação e nas emoções, destacando o poder de o cinema dirigir e controlar esses elementos subjetivos, pelo movimento e domínio da câmera sobre a imagem na tela, em contraste com o palco do teatro, que permitiria ao espectador certa liberdade para conduzir esses mesmos elementos diante do espetáculo.
}

uma imagem. Ou, quem sabe já, todos conscientes de que sempre somos já e só imagens para os outros e nos outros.

Uma sociedade que se faz nessa dinâmica precisa que as subjetividades possam transitar entre os pólos de circulação de imagens para que a objetivação dialogue com subjetivação. É preciso ser simultaneamente, espectador e espectado, como também consumidor e produtor de imagens, significados e discursos. Nesse sentido, as experiências com a produção fotográfica para a produção de filmes de animação em stop motion na educação ganha relevância estratégica, pois coloca no centro de sua artesania produtiva as questões sobre representação e tempo. Tudo é construído e falso naquilo que aparece animado e real no filme de animação finalizado. A velocidade e a aceleração, que cria vida e movimento, provêm de imobilidades, fixações, instantes, que custam muito tempo e sincronia para serem produzidos.

Ao se fazer animações em stop motion dentro de instituições de educação, essas ganham a oportunidade de abrir uma janela temporal e tecnológica no fluxo digital acelerado. Fluxo que, no encontro com nossa dificuldade humana de acompanhar, termina nos colocando prioritariamente na condição de espectadores. Mesmo quando produzimos, como o fazemos velozmente, não temos tempo para uma criativa e cuidadosa construção de nossas subjetividades, não há invenção, somente reprodução. Seguimos automaticamente, como espectadores de nós mesmos. Mas o que mais ganhamos ao passarmos da condição de espectadores à de produtores de imagens? 


\section{Benjamin, Imagem Dialética e a Reprodutibilidade Técnica}

Walter Benjamin nos ajuda a compreender a questão da imagem de modo a condensar as mudanças inauguradas pela modernidade. Um conceito central de sua obra, que contribui para a reflexão sobre a imagem e os usos da animação em stop motion na educação, é o conceito de imagem dialética. Nele, temos uma dinâmica que pode nos ajudar a pensar a imagem na época de sua reprodutibilidade técnica e tecnológica e as implicações para sua recepção mais consciente e ativa.

A imagem dialética aparece de forma enfática no livro das Passagens e tal ideia remete a uma reconstrução da realidade, na medida em que cada elemento que a compõe pode se defrontar com novas e renovadas totalizações que negam e, por vezes, escamoteiam os demais elementos de uma totalidade dada. Benjamin (2006) conseguiu perceber que do movimento de uma imagem a outra é possível um salto revolucionário, que permita perceber sentidos latentes que são possíveis quando tais imagens se apresentam na sua imobilização, desde que o sujeito que o estuda se coloque em um movimento de busca do sentido latente que existe atrás do sentido manifesto. No Projeto das Passagens, Benjamin afirma:

[...] a imagem é aquilo em que o ocorrido encontra o agora num lampejo, formando uma constelação. Em outras palavras: a imagem é a dialética na imobilidade. Pois, enquanto a relação do presente com o passado é puramente temporal e contínua, a relação do ocorrido com o agora é dialética - não uma progressão, e sim uma imagem, que salta. Somente as imagens dialéticas são imagens autênticas [...]. (BENJAMIN, 2006, p. 504)
A imagem dialética é a potência de transformação que advém da capacidade de pararmos o fluxo ininterrupto de um tempo quantitativo, homogeneizador (próprio da modernidade), instalando um tempo qualitativo, um tempo intensivo, fruto de interrupções significativas, capazes de respeitar os diferentes modos de processamento e de relação dos sujeitos com a realidade, em suas experiências e aprendizados. Por isso, a imagem dialética é uma imagem privilegiada do tempo histórico, que o apresenta em sua imobilidade - porque a capacidade de parar possui um potencial transformador, principalmente quando guarda, em sua imobilização, as contradições que um tempo carrega, que nosso tempo moderno necessariamente traz - o que é especialmente pertinente para nós, contemporaneamente.

Para Benjamin (1986a), em cada momento histórico existe a possibilidade de novos sentidos, de reconstrução de seus elos. Ele percebeu que, quando tomamos consciência de um objeto, de um aspecto dele pelo menos, deixamos de perceber outros. Os sujeitos, ao existirem somente em relação ao mundo, existem, também, vislumbrando um recorte do mesmo. Se o olho, então, somente toma consciência de um aspecto do objeto, conclui Benjamin (1986b) que há um certo inconsciente ótico (conceito que sistematizaremos mais adiante) ligado ao modo como o homem percebe o mundo. Com efeito, em sujeitos de espírito dialético, Benjamin (2006) diria que a imagem dialética é uma imagem sugestiva que salta, aparece, pisca, como que um flash de luz, reveladora de uma verdade, que antes era latente. Daí, a possibilidade de revolução. Portanto, a atenção para com os elos, com as associações, que se mostram como fixos e naturais, o modo como eles são formados e elaborados, é uma prática indispensável para a 
leitura das imagens numa lógica benjaminiana. Neste sentido, contribui a análise de Benjamin em seu Sobre o Conceito de História:

[...] pensar não inclui apenas o movimento das ideias, mas também sua imobilização. Quando o pensamento para [...] numa configuração saturada de tensões, ele lhes comunica um choque, através do qual essa configuração se cristaliza enquanto mônada [...]. (BENJAMIN, 1986a, p. 231)

Comparativamente a uma máquina fotográfica, a mente humana imprime, em seu espírito, as imagens. O fato para o qual Benjamin chama a atenção é que há uma imobilidade das imagens em seu movimento, que pode se apresentar seja na memória de uma simples máquina fotográfica, seja no interior da memória humana. A imagem dialética é necessariamente a percepção de um objeto que se apresenta através de seus opostos, produz um choque e amplia-se através de vinculações inéditas, construindo um novo todo.

Ao se trabalhar com imagens em qualquer situação educacional, através do stop motion inclusive, podemos estimular no aprendiz uma percepção dos elos que existem entre uma imagem e outra, num processo de reconhecimento do encadeamento de imagens na construção de uma narrativa, que pode vir a se tornar hegemônica. Tal aprendizagem contribui também para o desenvolvimento do questionamento reconstrutivo do objeto, justamente através da possibilidade dessas reconstruções ou revoluções serem percebidas nos elos construídos pela história oficial de homens e de objetos, podendo o aluno, e o professor, tal como

\footnotetext{
4 O conceito de mônada, inspirado em Leibniz, associa-se à ideia de que a parte contém a totalidade, se destaca na obra de Walter Benjamin na medida em que entende que cada elemento, uma vez captado como elemento isolado, pode constituir, como parte, uma totalidade.
}

o historiador crítico benjaminiano, reconstruir a causalidade (passado) com ponto de fuga no presente (que esteve latente até então) para, em seguida, suscitar novas esperanças para o futuro.

Os sujeitos são levados a criar, através do stop motion, com certa exigência de autonomia de pensamento, processos históricos, na medida em que constroem uma história através da associação de imagens, por meio da fotografia. Reiteramos, portanto, que a correlação pedagógica do stop motion com a educação não é uma substituição deste pelo texto, mas sim algo que permite ao discente fazer a passagem da minoridade à maioridade, passando da relação passiva do mundo de objetos, dados a partir de um sentido já constituído, para imagens organizadas por eles para a construção de um mundo autoral e cheio de significado.

$O$ universo que permite a construção do conceito de imagem dialética está associado ao surgimento da fotografia e das artes reprodutivas, que se constituem a partir da montagem, revelando o que Benjamin (1986b) chamou de inconsciente ótico. O inconsciente ótico é revelado porque "[...] a natureza que fala à câmera não é a mesma que fala ao olhar; [...] porque substitui a um espaço trabalhado conscientemente pelo homem, um espaço que ele percorre inconscientemente [...]" (BENJAMIN, 1986b, p. 94). Desta forma, detalhes, ênfases, destaques, redefinem os enquadramentos do que constitui a realidade ordinária, revelando-a como relativa, como não substancial. Ao mostrar a realidade a partir de aspectos existentes, mas desconhecidos, é possível reconhecer que o que constrói o olhar e a compreensão de mundo associa-se àquilo que é, na verdade, apenas um aspecto, um recorte, que naturaliza e universaliza o que é apenas uma parte.

Neste mesmo sentido, a questão da montagem contribui para o reconhecimento do 
aspecto de construção do real. Para Benjamin (2006), a montagem, presente no cinema e nas artes de vanguarda, desnaturaliza a compreensão do mundo como um todo orgânico, um lugar familiar já dado e constituído. A montagem refere-se ao tratamento do material, com "[...] a separação das partes do seu contexto [...]" (BURGER, 1993, p. 124) seguido de "[...] ajuste dos fragmentos e fixação de sentido [...]" (BURGER, 1993, p. 124). A questão central na montagem é a "[...] criação de significado através da justaposição de elementos [...]" (KANGUSSU, 2012, p. 7).

Sendo assim, a proximidade com os aspectos que compõem a imagem permite um acesso ao mundo contemporâneo, na medida em que esta, através da montagem, constitui modos de criação do real. Através da experimentação com a imagem, na condição de um produtor ativo, estudantes podem se tornar conscientes do caráter montado do mundo, entendendo que é preciso sempre reconhecer tal dimensão e identificar as estratégias de constituição de sentidos em cada situação ou contexto. Dessa forma, entendemos que o trabalho com o stop motion pode colocar os alunos em condição de perceber tanto o modus operandi de organização da imagem (em seus diferentes veículos), quanto o caráter construído da realidade cultural, social, política, na medida em que tudo depende de com que peças se pretende trabalhar e de que modo decidimos contar uma história.

\section{Experimentações com Stop Mo- tion}

Um dos objetivos centrais da educação formal é fazer com que os alunos conquistem a autonomia de pensamento pela aprendizagem de uma série de disciplinas específicas. Em se tratando de estudantes que serão professores, e que precisarão multiplicar esta conquista, sua educação exigiria atenção ainda maior. Entendemos que os alunos hoje tendem a considerar as aulas monótonas e, ao contrário, os computadores e a internet como bons e prazerosos. Também as mídias e seus conteúdos de entretenimento como: moda, propaganda e publicidade, tendem a ser valorizados pelos discentes, sendo muitas vezes responsáveis por formar suas identidades. Sendo assim, caberia a todos os profissionais ligados à educação, pensar disciplinas e atividades relacionadas ao uso pedagógico da imagem, como o que podemos fazer com o stop motion. É válido que profissionais da educação trabalhem para um ensino que permita ao discente a compreensão do elemento de montagem, tal como apresentamos antes, uma vez que este envolve o processo de construção da realidade social e de assimilação das coisas que, igualmente, podem ser provocadas por uma oficina de stop motion e, assim, pensar a imagem teoricamente e em suas possibilidades de aplicação prática.

O estudante que participa do processo de montagem de um filme de stop motion pode perceber que, entre as imagens da grande mídia e as de uma produção fotográfica feita em sala de aula, há princípios partilháveis, porém, com sutil distinção. As imagens da mídia comumente carregam a tendência de levar seus espectadores a desconsiderar aspectos complexos da vida e à passividade das faculdades intelectuais e criativas, ao passo que as imagens construídas a partir de uma oficina de stop motion tendem a levar o aluno que dela participa à descoberta de si mesmo, de forma ativa. Assim também podemos pensar a educação, impulsionada pelas ideias de Benjamin, como potencializando a ruptura de sentidos cristalizados, permitindo a construção de no- 
vos sentidos no trabalho conjunto de professores e alunos. Dessa forma, o stop motion é um exemplo de uso da imagem em sala de aula que potencializa o trabalho educacional - ligado à capacitação do estudante para lidar com os elementos próprios a seu tempo.

Nas oficinas e no curso que realizamos, pudemos encontrar alguns exemplos dessas tomadas de consciência, rupturas de sentido, e criação de histórias desejadas e refletidas. Em todas essas experiências, no entanto, os participantes inicialmente, se deparam com empecilhos no qual se viam obrigados a repensar sua participação, a expressão e a construção da imagem que desejavam apresentar nos filmes. Como exemplo, em primeiro lugar, a necessidade de traduzir uma ideia em imagens, que precisam simultaneamente ter a forma de fotos e poderem, posteriormente, assumirem o formato de um filme, respeitando seus cânones e sua gramática própria. O stop motion é uma atividade que traz consigo um desafio intelectual e um exercício cognitivo, além do lúdico e imaginativo, permitindo que os alunos, na elaboração dos filmes, exercitem suas ações de planejar decidir, selecionar, organizar e compreender os elementos e a relação entre eles para que as fotos virem filme. Assim, tivemos, por exemplo, o desafio e a preocupação com o enquadramento que cada imagem teria, de modo que permitisse contar uma história contínua sem inconsistências.

Outro fator importante a ser ressaltado é a capacidade de criação dos grupos, visto que eles tiveram de trabalhar com habilidades como as de síntese e de construção narrativa dentro de um espaço de tempo curto, além do exercício de se abrir um espaço para a escuta das diferentes vozes dos componentes do grupo. Dividir tarefas, compor opiniões e sugestões distintas, habilidades e características, que devem se expressar no final em uma unidade narrativa que é o filme realizado por todos é outro desafio, estimulando o trabalho em equipe. Apesar de haver uma divisão de tarefas, na realização de um filme de stop motion todos devem trabalhar juntos e sincronizados, caso contrário, a continuidade do movimento fica prejudicada. Todos devem mover seus elementos no mesmo ritmo, com a mesma amplitude, obedecendo ao enquadramento da máquina controlado por quem está tirando as fotos. Esta é já uma novidade e uma experiência de montagem e inconsciente ótico vivida na relação dos integrantes do grupo, que se faz visível na qualidade dos filmes. Muitas vezes vemos alunos acostumandos a fazer trabalhos em grupo onde dividem suas tarefas e trabalham isoladamente, de forma independente. No stop motion, tal fato é impossível, ao preço de o filme não convencer ninguém. Todo o entrosamento vivido pelo grupo transparece no resultado final do filme, em sua qualidade ou suas imperfeições.

Em uma oficina, em que os participantes queriam fazer um filme que mostrasse o roteiro de viagem que fariam ao oriente, como parte de uma pesquisa da qual estavam participando, tivemos o desafio de escolher os elementos narrativos que representassem simultaneamente o grupo de pesquisa, o objetivo da viagem e seu roteiro, e a base teórica que os inspirava. Como se tratava de seguir um roteiro já feito por Ibn Batuta, um aventureiro mulçumano no século XIV, objeto da tese de doutorado da coordenadora da pesquisa, o projeto da viagem tinha como nome de referência Nas Asas de Ibn Batuta ${ }^{5}$. Com isso, decidiram por

\footnotetext{
${ }^{5}$ Os estudantes integravam o Núcleo Interdisciplinar de Estudos sobre África, Ásia e as Relações Sul-Sul (NIEAAS), coordenado pela Profa Dra Beatriz Bissio (IFCS/UFRJ), cuja linha de pesquisa prioritária são os temas vinculados ao mundo africano e ao mundo árabe-islâmico do século $X X$ e as relações entre a África, a Ásia e a América Latina. A professora doutorou-se em história em 2008, no Curso de Pós-graduação
} 
fazer um filme com um pássaro voando sobre a imagem de um mapa da África, fazendo o percurso do roteiro da viagem. Tiveram, então, entre os desafios, o de desenhar três pássaros diferentes, mas com as mesmas proporções, com asas em posições diferentes, mas que, ao se trocar um pássaro por outro em cada foto, conseguissem o efeito de movimento de voo. Outro desafio foi encontrar a exata distância do mapa que gerasse uma imagem que permitisse a leitura do nome dos países, bem como a relação geográfica entre eles e a localização deles no continente. Um só ponto de vista que indicasse três informações geográficas e suas relações (Figuras 1 e 2).
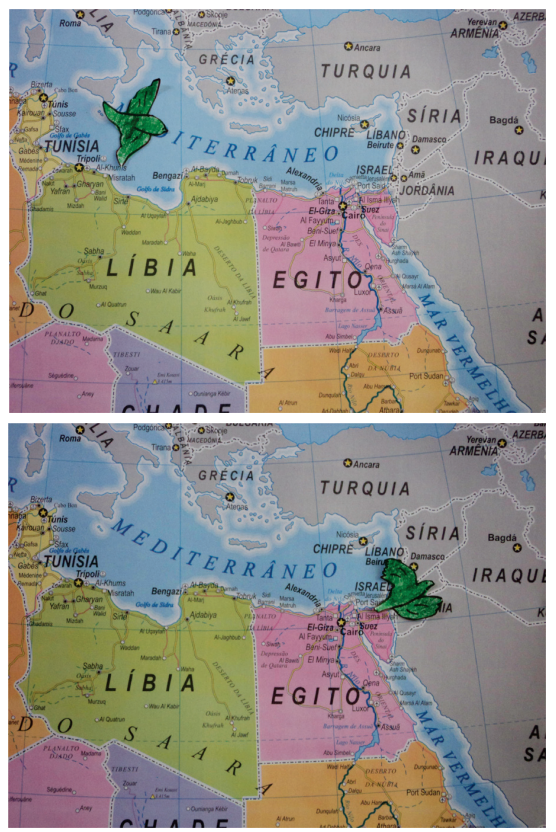

FIGURA 1-2 - Fotos da animação em stop motion "Nas asas de Batuta"

FONTE: Acervo de fotos das oficinas de stop motion do projeto ITEC.

em História, do Centro de Estudos Gerais da Universidade Federal Fluinense, em Niterói, com a tese Percepções do Espaço no Medievo Islâmico (Séc. XIV): o exemplo de Ibn Khaldun e Ibn Batuta.
Em outra oficina, o tema era fazer um filme sobre educação. Com o título "A Educação que Queremos, um dos grupos fez um filme em que, a partir da imagem de um globo terrestre, surge a figura de um menino, ao lado do qual, frases e palavras vão surgindo. Primeiro, surge a frase: Pense no futuro!, trazendo a imagem de que a educação forma jovens que serão responsáveis pelo futuro. Tal fato já revela uma visão de educação ligada a um projeto de mundo - temos o globo terrestre como primeira imagem - e não a um projeto individual. Depois surge a frase $A$ nossa educação precisa de ... e vão surgindo papéis amassados que são aos poucos desamassados, cada um contendo uma palavra: criatividade, esperança, afeto, amor, inclusão, sensibilidade, paz, alegria. É curioso notar que as palavras parecem ter sido descartadas, pois estão em bolas de folhas de papeis amassados, e precisariam regressar a educação. Seriam valores e características a serem retomadas na educação. Poucas referências a conteúdos ou técnica e muito mais referências a valores e sentimentos. Sendo um filme feito por estudantes de pedagogia, o que ele nos faz ver? O que nos faz pensar sobre como esses alunos entendem sua futura profissão e como, na condição de alunos, têm sentido e percebido o que se tem apresentado a eles? Do que sentem falta na sua formação como alunos? Outro ponto revelador é que palavras sejam as imagens escolhidas para fazer um filme sobre educação. Elas podem, talvez, revelar o quanto o texto é a marca para esse universo. Mesmo quando se pretende tratar dele com imagens e fotos, são imagens e fotos de textos que aparecem, imagens que devem ser lidas. No entanto, sua animação permite que outras sensibilidades estéticas deem novos sentidos a essas palavras, que agora não aparecem só escritas, mas sim, animadas (Figuras 3 e 4). 

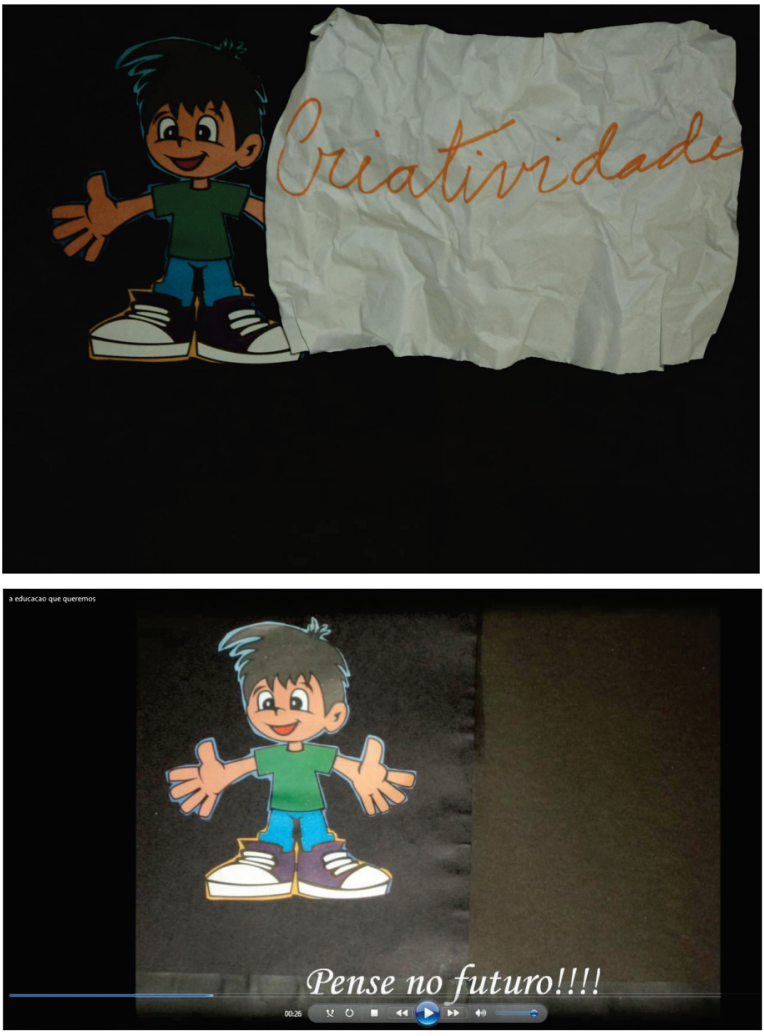

FIGURAS 3-4 - Fotos da animação em stop motion "A educação que queremos"

FONTE: Acervo de fotos das oficinas de stop motion do projeto ITEC.

Nesta mesma oficina, outro grupo fez um filme intitulado Escola, Lugar de Encontro. Eles montam um cenário em 3D, com cartolina onde há uma sala de aula com carteiras, um quadro com o alfabeto escrito e um pátio com uma árvore e um lago. Dois alunos estão em sala, cada um de um lado da mesma, vão se aproximando, se dão as mãos e saem da escola. Segue-se a frase Aprendendo juntos!. Mais uma vez, as letras parecem ser a marca da educação escolar, mas o principal não é o alfabeto no quadro, nem o espaço da escola. 0 que importa são os encontros, que nos levam para fora desse espaço, e o que levamos dos encontros que acontecem nesse espaço para fora dele. Também feito por estudantes de pedagogia, a dimensão humana e socializadora do trabalho educacional surge como o que está no imaginário mais direto desses futuros professores. No entanto, como ainda são alunos, podemos também ver que aquilo que muitos professores julgam ser um problema na escola, aparece como o principal dela, sua grande força quando se é aluno: trata-se de um lugar para fazer amigos, um lugar de encontros. (Figuras 4 e 5 )
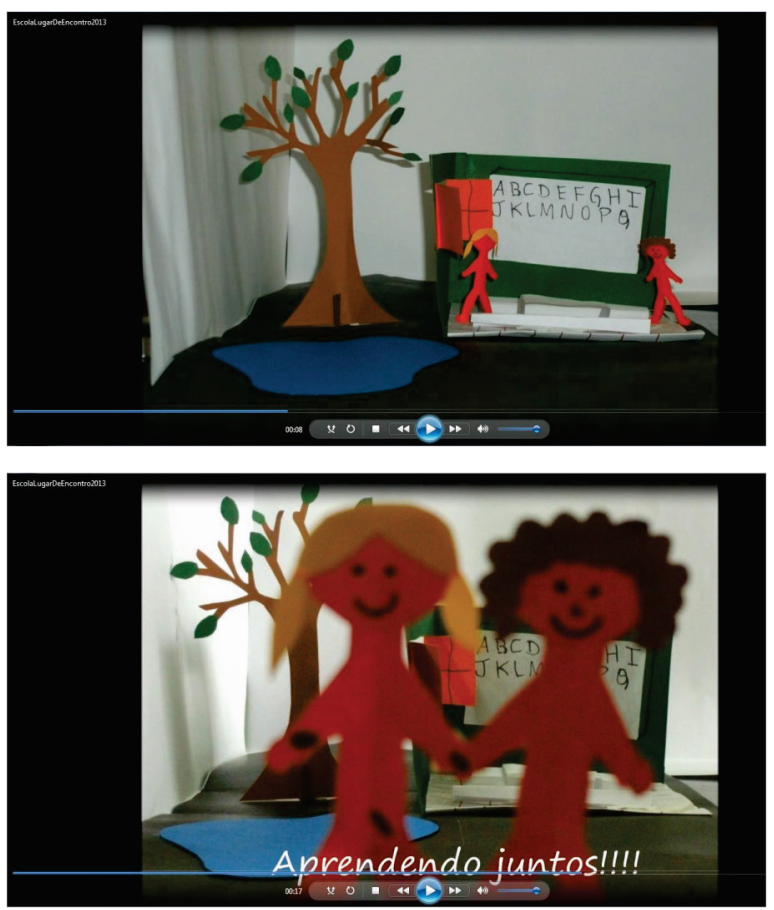

FIGURA 4-5 - Fotos da animação "Escola, lugar de encontro"

FONTE: Acervo de fotos das oficinas de stop motion do projeto ITEC

Em ainda outra oficina, o tema eram novas tecnologias e educação. Um grupo fez um filme a partir da frase do quadro de René Magritte, Ceci n'est pás um pipe, tornada Ceci n'est pas I'education. Utilizando a técnica de desenhos 
feitos em um caderno, que foram fotografados com um celular enquanto eram desenhados, os alunos fazem alusão aos recursos mais simples da educação: lápis e papel, quadro e giz. Quando animadas, as fotos dos desenhos fazem com que eles pareçam surgir sozinhos. Nos desenhos estão um professor que escreve em um quadro negro, alunos que dormem e um celular toca no bolso de um aluno. A imagem do celular desenhado é substituída por um de verdade, onde aparecem imagens das manifestações que tomaram as ruas do Brasil, em junho de 2013, contra o aumento das passagens de ônibus, a corrupção e o desvio de recursos públicos para a realização da Copa do Mundo de Futebol. Ao final, a frase Ceci est I'education aparece escrita na tela do celular. Este filme é particularmente rico, pois mescla o tradicional com o moderno, refletindo bem o momento contemporâneo e também a situação da educação e a própria técnica do stop motion. Com o mais rudimentar se fez um filme potente em termos de sentido, o qual só foi possível pela tecnologia digital disponível em smartphones, que permitiram tirar e buscar fotos na internet, tudo dentro da sala de aula, utilizando o mesmo aparelho. O aparelho, que parece muitas vezes vilão da escola, neste momento, foi um grande aliado para a realização da oficina. Novo sentido e função foram dados a este objeto tão cotidiano, o celular, e ao ato trivial de fotografar. Novos sentidos e funções também foram dados aos bons e velhos lápis e caderno, alçados a protagonistas do filme pelos desenhos (Figuras 5 e 6).
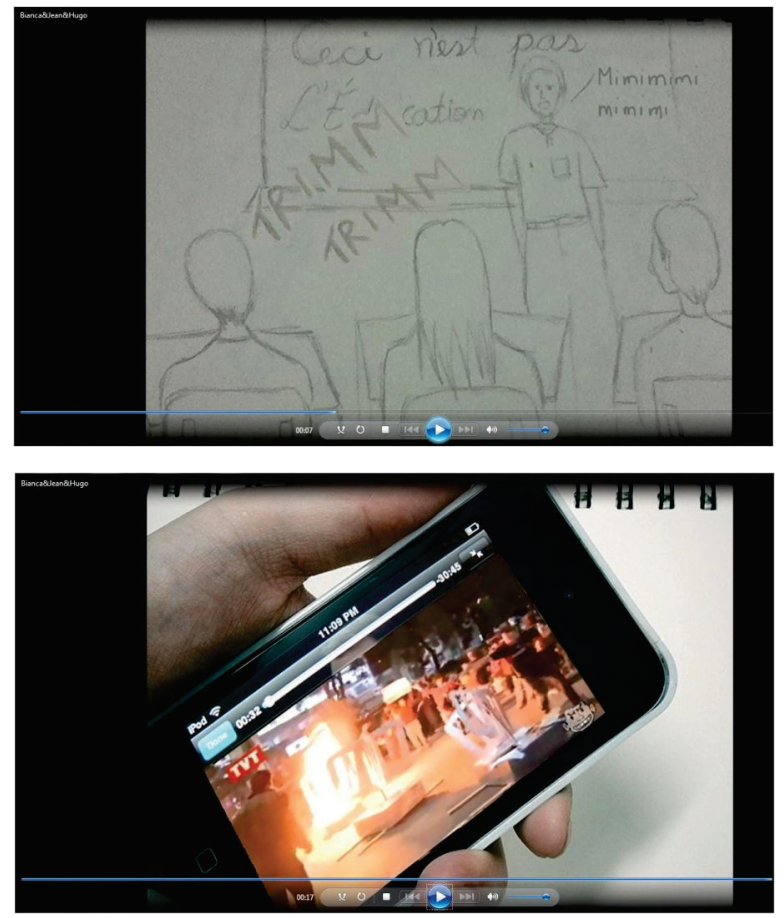

FIGURAS 5-6 - Fotos da animação "Ceci n'est pas l'education"

FONTE: Acervo de fotos das oficinas de stop motion do projeto ITEC.

Dessa forma, foi possível perceber como essa técnica de animação propicia a resignificação dos objetos que outrora faziam parte de seu cotidiano, mas eram banalizados, o que em certa medida se conjuga com o conceito benjaminiano de inconsciente ótico, ao tornar visível o que antes não era percebido conscientemente, potencializando uma riqueza de sentidos em objetos ordinários. Além disso, os alunos entram em outro tempo na medida em que saem do digital e vão para o analógico, fazendo a experiência de um tempo mais lento, permitida pelo trabalho manual que a técnica exige. Nesta outra temporalidade, podem vivenciar e entender o processo de construção das cenas que serão fotografadas. Outro conceito citado anteriormente, que aparece de 
forma direta, é o de montagem em que cada parte, no caso, cada foto, representa uma parte constituinte de um todo, e, no conjunto do filme, constrói um sentido inédito. Já a imagem dialética, como potência de transformação e construção de novos sentidos, pode ser exercitada pelo trabalho artesanal que envolve o fazer do stop motion, que instaura um tempo e uma narrativa que se mostra significativa pelo fato de deter/lentificar o tempo.

Essa ressignificação das imagens torna-se cada vez mais urgente, numa atualidade em que cada vez mais as relações são intermediadas por imagens produzidas e propagadas via tecnologias digitais. Assim, a utilização de uma técnica que usa de dada tecnologia computacional de edição de imagens, paralela a uma coordenação pedagógica que tem como único e exclusivo papel o de fazer dos sujeitos, estudantes pensadores autônomos (capazes de pensar de maneira autoral e criativa), a técnica do stop motion na escola e na universidade pode influenciar positivamente as formas de organização social de nossa contemporaneidade, treinando o olhar para elementos mais significativos. A experiência de utilização pedagógica dessa técnica, permite compreender as relações comunicacionais através de tecnologias digitais contemporâneas, conjugado a um processo de troca e produção de imagens dentro de uma outra dinâmica. Acreditamos que o stop motion pode ser inserido no ensino numa perspectiva de sensibilização, partindo da visão do estudante que se relaciona com determinadas imagens em sua vida cotidiana, a fim de auxiliar um trabalho educacional voltado para interação do texto e da imagem, despertando no mesmo a necessidade de dar novos sentidos à realidade, incitando-o a sair de uma postura de passividade para a de atividade.

\section{Referências}

BARTHES, R. A Câmara Clara: nota sobre a fotografia. Rio de Janeiro: Nova Fronteira, 1984.

BENJAMIN, W. Sobre o Conceito de História. In: BENJAMIN, W. Obras Escolhidas: magia e técnica, arte e política. São Paulo: Brasiliense, 1986a. V. 1, p. 222-232.

BENJAMIN, W. Pequena História da Fotografia. In: BENJAMIN, W. Obras Escolhidas: magia e técnica, arte e política. São Paulo: Brasiliense, 1986b. V. 1, p. 91-115.

BENJAMIN, W. Passagens. Belo Horizonte: Ed. UFMG, 2006.

BURGUER, P. Teoria da Vanguarda. Lisboa: Vega, 1993.

CHARNEY, L.; SCHWARTZ, V. O Cinema e a Invenção da Vida Moderna. São Paulo: Cosac\&Naify, 2004. 
KANGUSSU, I. Desvios: citação, montagem, mosaico. In: ACADEMIA.EDU. [S.I.: s.n], [2012?]. Disponível em: <http://www.academia.edu/858092/DESVIOS_CITACAO_MONTAGEM_MOSAICO> Acesso em: 15 mar. 2014.

PRZYBLYSKI, J.M. Imagens (Co)moventes: fotografia, narrativa e a comuna de Paris de 1871 In: CHARNEY, L.; SCHWARTZ, V. O Cinema e a Invenção da Vida Moderna. São Paulo: Cosac\&Naify, 2004. P. 289-315.

SCHWARTZ, V. O Espectador Cinematográfico Antes do Aparato do Cinema: o gosto do público pela realidade na Paris fim de século. CHARNEY, L.; SCHWARTZ, V. O Cinema e a Invenção da Vida Moderna. São Paulo: Cosac\&Naify, 2004. P. 337-360.

XAVIER, I. (Org.). A Experiência do Cinema: antologia. Rio de Janeiro: Ed. Graal; Embrafilmes, 1983.

Aline Veríssimo Monteiro: Universidade Federal do Rio de Janeiro - Rio de Janeiro - RJ - Brasil. Email: alinevemonteiro@gmail.com

Angela Medeiros Santi: Pontifícia Universidade Católica do Rio de Janeiro - Rio de Janeiro - RJ - Brasil. Email: am-santi@uol.com.br

Aurélia Navarro de Andrade Cintra Ferreira: Universidade Federal do Rio de Janeiro - Rio de Janeiro - RJ - Brasil.Email: andeacferreira@gmail.com 